\title{
A CONSTITUIÇÃO DO CONCEITO DE SANTIFICAÇÃO NA IGREJA ADVENTISTA DO SÉTIMO DIA: REVISITANDO OS PRIMÓRDIOS DENOMINACIONAIS ${ }^{1}$
}

\author{
THE CONSTITUTION OF THE CONCEPT OF SANCTIFICATION IN THE SEVENTH DAY \\ ADVENTIST CHURCH: REVISITING THE DENOMINATIONAL BEGINNINGS
}

Fábio Augusto Darius*

\section{Resumo:}

O presente artigo versa acerca do desenvolvimento do conceito de santificação na Igreja Adventista do Sétimo Dia a partir de suas premissas históricas. Almeja, portanto, revisitar suas fontes iniciais buscando concluir se hodiernamente ainda a presente denominação mantém seu postulado de outrora. Para os adventistas do sétimo dia, a perspectiva da Parousia visível e literal (Ap 1.7), bem como a questão da mortalidade da alma, desde seus inícios mantém-se, ao menos sob o aspecto doutrinário, inalterado. Para fomentar a discussão, fez-se uso de autores contemporâneos como tentativa de diálogo extramuros.

Palavras-chaves: Igreja Adventista do Sétimo Dia; Santificação; Parousia; Mortalidade da Alma.

\section{Abstract:}

This article, result of research for postgraduate studies, is about the construction of the concept of sanctification in the Seventh-Day Adventist Church starting from its historical premises. The purpose of the article is to revisit its initial sources in order to conclude whether the present denomination still maintains its postulate. For Seventh-Day Adventists Church members, Parousia visible and literal (Rev 1.7), and the quest of mortality continues unaltered. To encourage a discussion, was used contemporary authors as an attempt to dialogue outside the walls.

Keywords: Seventh-Day Adventist Church; Sanctification; Parousia; Mortality of the Soul.

Introdução

A gênese do movimento adventista do sétimo dia, tensa e atribulada por seu caráter notadamente apocalíptico, apolítico e interdenominacional ainda hoje suscita as mais diversas discussões a partir de um amplo escopo de visões muitas vezes anacrônicas. Acerca desse tema, o autor já publicou neste mesmo periódico um texto, aludindo a outros que ainda servem como fonte
\end{abstract}

1 Enviado em: 07.05.2018. Aceito em: 09.06.2020.

* Doutor e Mestre em Teologia pela Faculdades EST, São Leopoldo, RS. Graduação em História pela Fundação Universidade Regional de Blumenau FURB. Docente no Centro Universitário Adventista de São Paulo, Campus Engenheiro Coelho. Atua no Mestrado Profissional em Educação e no Curso de Licenciatura em História. E-mail: fabio.darius@unasp.edu.br

Protestantismo em Revista | São Leopoldo | v. 45, n. 02 | p. 100-110| Jul./dez. 2019

Disponível em: <http://periodicos.est.edu.br/index.php/nepp> 
inicial de leituras ${ }^{2}$. Naquele breve período de pouco mais de uma década, entre 1831 e 1844 , a iminência do fim dos tempos para o citado grupo - através de uma análise conjuntural muito particular de certos textos bíblicos - fez da preparação para a volta de Cristo o único e exclusivo tema das pregações desses ministros milenaristas. De fato "pode-se claramente afirmar que o milerismo era um movimento de uma doutrina só: a doutrina da volta de Jesus. Seus ministros podiam responder publicamente apenas sobre esse tema" ${ }^{3}$.

William Miller, o precursor do movimento e seu primeiro pregador, imbuído do cientificismo racionalizante da primeira metade do século XIX, não sistematizou suas premissas teológicas de cunho apocalíptico. Nem mesmo seus ministros o fizeram. O legado documental desse movimento são panfletos com sermões e explicações doutrinárias, bem como um pequeno e extinto jornal, com nove edições, o Advent Herald, de caráter marcantemente apologético. Além disso, um gráfico simplesmente conhecido como 1843 foi confeccionado pelos evangelistas do movimento, mostrando precisamente o então atual momento da história como o mais solene e último deles, antes do início da reestruturação do planeta com a extinção do pecado.

Devido à urgência desta mensagem e pragmatismo de seus arautos, não é possível encontrar de forma clara um conceito, ainda que embrionário, de santificação ou de qualquer outra doutrina a não ser a partir dos próprios textos bíblicos citados por Miller ${ }^{4}$. Estes textos, além dos próprios versículos de Daniel e Apocalipse, eram, em grande medida, os escritos de Paulo aos Gálatas, acerca dos frutos do espírito em contraposição às obras da carne, dentre outros que facilmente permitiam acepções concretas. Portanto, a construção conceitual do termo no seio do movimento foi iniciada a partir da práxis discursiva de Miller.

\section{A práxis da santificação e seus problemas}

A preparação para a volta de Jesus requeria de seus adeptos, de fato, a aplicação prática dos sermões, sempre que possível fosse. Assim, pais e filhos promoviam reconciliação, antigas dívidas eram pagas e todo um ambiente de serenidade era tecido, apesar da grande e crescente hostilidade por parte de um não pequeno grupo de céticos, oriundos de dentro e fora das igrejas cristãs estabelecidas.

De fato, Miller havia fomentado, direta ou indiretamente, um grupo de cristãos não identificados ou classificados como pertencentes a qualquer outro grupo denominacional e devidamente institucionalizado. Porém, esse novo grupo tinha a certeza, ainda que também fundamentada pela lógica da interpretação histórica adventista, e não somente pela fé, de que possuía e estava com a verdade. No primeiro livro de Ellen White uma das fundadoras do adventismo do sétimo dia, essa acepção pode ser facilmente compreendida, ao ela afirmar que:

2 DARIUS, Fábio Augusto; WACHOLZ, Wilhelm. De corpo, alma e espírito: apontamentos históricos e teológicos acerca do tema santificação na obra holística de Ellen White. Escola Superior de Teologia, São Leopoldo, 2014. DARIUS, Fábio Augusto. O reavivamento milerita (1831-1844): esperando Cristo voltar. Protestantismo em Revista, v. 18, p. 56-65, 2009. TIMM, Alberto. Antecedentes históricos da interpretação bíblica adventista. In: REID, GEORG (Org.). Compreendendo as Escrituras: uma abordagem adventista. Engenheiro Coelho: UNASPRESS, 2007. MAXWELL, C. História do Adventismo. Santo André: Casa Publicadora Brasileira, 1982.

3 KNIGHT, George. Em busca de identidade: o desenvolvimento das doutrinas adventistas do sétimo dia. Tatuí: Casa Publicadora Brasileira, 2005, p.73.

4 A Enciclopédia Ellen White, publicada em português em 2008, fornece alguns elementos que sugerem bibliografias acerca dessa temática. Contudo, o texto ainda não clarifica a questão. Para mais informações, veja FORTIN, Denis; MOON, Jerry (Eds.). Enciclopédia Ellen G. White. Tatuí: Casa Publicadora Brasileira, 2018.

Protestantismo em Revista | São Leopoldo | v. 45, n. 02 | p. 100-110| Jul./dez. 2019

Disponível em: <http://periodicos.est.edu.br/index.php/nepp> 
Nós que cremos na verdade devemos ser muito cuidadosos para não dar ocasião de falarem mal de nossas virtudes. Devemos ter certeza de que todo passo que dermos esteja de conformidade com a Bíblia, pois aqueles que odeiam os mandamentos de Deus triunfarão sobre nossos erros e faltas, como fizeram os ímpios em $1843 .^{5}$

O citado texto, que revisitou os acontecimentos de 18436, deixa claro que o grupo internamente se considerava como o exclusivo receptor da salvação por ser o exclusivo detentor da verdade. Havia portanto, notadamente, uma distinção por parte desses adventistas entre eles mesmos e os outros integrantes da sociedade, cristãos professos ou não. Deste modo - exatamente por isso - a estigmatização por parte dos não-adventistas não se lograva exitosa, em primeiro lugar porque esses adventistas, apesar de minoritários, se consideravam superiores pois justamente eram os exclusivos possuidores da verdade, mas não só: além dessa acepção particular da verdade transcendental, menos preconizada, estava aliado o "descobrimento" e entendimento dos textos que mostravam a iminência do fim, pela via da cognição. Paradoxalmente, era a humildade cristã expressa no grupo, a partir da busca da perfeição necessária para deixar esse mundo, que evidenciava essa pretensa superioridade. Eis novamente, a procura, ainda não sintetizada, da santificação como claro pressuposto de inclusão nesse grupo, legitimado por meio único da fé e da razão moderna.

Segundo Norbert Elias e John Scotson, um grupo só pode estigmatizar outro com eficácia quando está bem instalado em posições de poder das quais o grupo estigmatizado é excluído. ${ }^{7}$ Não havia, nesse caso específico, um poder temporal que pudesse estigmatizar o movimento. Na verdade, o próprio grupo foi por ele mesmo, em grande medida, estigmatizado quando do desmoronamento de sua fé racional, com o não aparecimento de Cristo nas nuvens do Céu, de acordo com suas próprias predições. A implosão do movimento, nesse caso, aconteceu de dentro para fora, com a quebra total do paradigma de coesão. Segundo White, em escrito posterior, isso não poderia ser diferente, visto que

Não é a oposição do mundo o que mais ameaça a igreja de Cristo. É o mal abrigado no coração dos crentes que acarreta suas mais graves derrotas, e mais seguramente retarda o progresso da causa de Deus. Não há maneira mais certa de debilitar a espiritualidade que acariciar a inveja, a suspeita, a crítica e as vis desconfianças. Por outro lado, o mais forte testemunho de haver Deus enviado Seu Filho ao mundo é a existência de harmonia e união entre os homens de variados temperamentos que compõe Sua igreja. ${ }^{8}$

De acordo com Thomas Kuhn, paradigma é uma forma culturalmente determinada e socialmente compartilhada de valorar, interpretar e intervir na natureza, na sociedade e na história. ${ }^{9}$ No caso do movimento estudado, pelo fato dos seus valores se inserirem em um plano supra histórico a partir de uma interpretação histórica particular é que justamente ocorreu o

5 WHITE, Ellen. Primeiros Escritos. Tatuí: Casa Publicadora Brasileira, 2007. p. 70.

6 O ano de 1843 foi atribuído pelo grupo aqui explanado como aquele em que Cristo ressurgiria, resgatando os seus filhos. Posteriormente, a data foi prorrogada para 1844, dia 22 de outubro. Desde aqueles dias, porém, com o não surgimento de Cristo conforme as expectativas de muitos, surgiu uma nova perspectiva, sistematizada em crença fundamental da Igreja Adventista do Sétimo Dia: em 22 de outubro de 1844 algo cósmico se deu: a passagem de Cristo do lugar Santo para o Santíssimo, onde começou o juízo investigativo, passo imediatamente anterior ao seu regresso, aí sim, visível e literal.

7 ELIAS, Nobert; SCOTSON, John. Os estabelecidos e os outsiders: sociologia das relações de poder a partir de uma pequena comunidade. Rio de Janeiro: Jorge Zahar, 2000, p. 23.

8 WHITE, Ellen. Atos dos Apóstolos. Tatuí: Casa Publicadora Brasileira, 2007, p. 549.

9 KUHN, Thomas. A estrutura das revoluções científicas. São Paulo: Perspectiva, 1992, p. 218.

Protestantismo em Revista | São Leopoldo | v. 45, n. 02 | p. 100-110| Jul./dez. 2019

Disponível em: <http://periodicos.est.edu.br/index.php/nepp> 
rompimento pela constatação dessa falibilidade do eixo central. Foi essa ruptura que minou os pressupostos teóricos do movimento, abalando a fé que daí se originava. Isso obrigou seus membros remanescentes a se firmarem muito mais alicerçados, necessariamente, no paradigma da fé, ainda que legalista. Precisamente nesse ponto da história do movimento, seus membros viveram à beira da falésia afastados das já antigas certezas e próximos da inquietude. É a partir desse grande acontecimento, que internamente, a exemplo dos cristãos primitivos, conforme escrito de Ellen White, o grupo ruiu, se dividindo em vários outros. Segundo ela:

Os crentes começaram a olhar os defeitos uns dos outros. Demorando-se sobre os erros, dando lugar a severo criticismo, perderam de vista o Salvador e Seu amor. Tornaram-se mais estritos na observância de cerimônias exteriores, mais rigorosos na teoria que na prática da fé. Em seu zelo para condenar os outros, passavam por alto seus próprios erros. Perderam o amor fraternal que Cristo Ihes ordenara, e, o que é mais triste, não tinham consciência dessa perda. Não reconheceram que a felicidade e a alegria lhes estavam abandonando a vida, e que, havendo excluído o amor de Deus do coração, estariam logo andando em trevas. ${ }^{10}$

\section{Santificação como "a" diferença entre os "outros" protestantes}

Uma das diferenças teológicas básicas entre os mileritas e os adventistas do sétimo dia é a concepção da chamada "primeira mensagem angélica" expressa no capítulo XIV do livro de Apocalipse. Segundo Knight:

Enquanto os mileritas haviam associado a cena de juízo de Daniel 7 à purificação do santuário de Daniel 8:14 e à chegada da hora do Seu juízo de Apocalipse 14:7 com o juízo a ocorrer no segundo advento, os sabatistas passariam a interpretar essas passagens como se referindo a um juízo pré-advento (ou, como eles o chamavam, um juízo investigativo. ${ }^{11}$

Além disso, não estando mais apenas entrelaçado na questão da volta de Jesus, a mensagem do Sábado passou a vigorar como central, bem como a doutrina distintiva do santuário celestial, perspectiva única entre as igrejas cristãs. A partir da formação desse quadro, a identidade adventista é formada ainda que embrionariamente, muito embora a concepção exclusivista de detentora da verdade fosse, tal qual seu movimento originador, bastante presente. ${ }^{12}$ O historiador Knight comenta que:

Os adventistas sabatistas verdadeiramente tinham encontrado sua identidade. Passaram a se considerar o povo da profecia. Por causa de suas convicções, muitas vezes se referiam a seu movimento como a -terceira mensagem angélicall. A seu ver, o tempo da dispersão que se seguira ao desapontamento de outubro de 1844 havia acabado e chegara o tempo do ajuntamento, durante o qual deviam pregar sua mensagem escatológica aos remanescentes do milerismo. ${ }^{13}$

10 WHITE, 2007, p. 548.

1 KNIGHT, 2005, p. 80

12 Apenas em 1998, a Federação Luterana Mundial reconhece oficialmente os adventistas como continuadores da Reforma e os adventistas reconhecem que não são os exclusivos remanescentes, ou seja, os únicos possuidores da verdadeira doutrina, conforme acentuado por: KILPP, Nelson. FEDERAÇÃO LUTERANA MUNDIAL. GENERAL CONFERENCE OF SEVENTH-DAY ADVENTISTS. Lutherans and Adventists in conversation: Report and papers presented 1994-1998. Silver Springs: General Conference of Seventh-day Adventists, Geneva: Lutheran World Federation, 2000.

13 KNIGHT, 2005, p. 78.

Protestantismo em Revista | São Leopoldo | v. 45, n. 02 | p. 100-110| Jul./dez. 2019

Disponível em: <http://periodicos.est.edu.br/index.php/nepp> 
De qualquer forma, pregação inicial deveria ser, ao menos segundo os objetivos da igreja, estendidos a todos os cantos do mundo, para que a luz da verdade fosse universalmente resplandecida. Isso pode ser evidenciado em White:

Nosso campo é o mundo. Repito de novo e de novo. Nosso campo é o mundo ${ }^{14}$. Nós nos regozijamos por aqueles que alegremente têm oferecido seus bens ao Senhor. Nós encorajamos todos a ajudar com seus recursos para a causa de Deus. Cristãos que se encontram plenamente despertos à necessidade do trabalho não gastarão o dinheiro destinado ao Senhor desnecessariamente. ${ }^{15}$

Além dos fatores acima apresentados, há ainda outros que, em conjunto, podem ajudar a constituir teologicamente as diferenças entre os adventistas do sétimo dia e os outros grupos também oriundos do movimento de Miller. É importante visualizar que em todos os outros, o tema da santificação é constantemente abordado, mas de forma bastante diversa da denominação em questão. Conforme Butler, ao comparar outros milenaristas da época como os mórmons e as testemunhas de Jeová, historiadores e sociólogos, consideram extraordinária a rápida transição da instabilidade pós-milerita para a organização bastante estável e uniforme alcançada pela Igreja Adventista do Sétimo Dia. Sugerem-se, assim, cinco razões para esses fenômenos na expansão dos adventistas sabatistas:

Primeiro, o movimento não emergiu simplesmente como um corpo adventista separado, mas em decepção com o advento e após a reformulação das ideias; segundo, desde o início, seu milenarismo era uma entre várias preocupações, pois o grupo não apenas pregava o advento, mas as condições para ele; terceiro, essas condições foram validadas pela inspiração divina, pela qual o grupo adquiriu uma fonte independente de inspiração, além das Escrituras (...); quarto, o movimento estabeleceu um ministério profissional que abriu caminho para outras agências especializadas que o desmembraram de origens mais igualitárias; quinto, o aumento das preocupações com educação, dieta, assistência médica, liberdade religiosa e o sabatismo avançou ainda mais sua denominacionalização, tanto ideológica quanto institucionalmente. ${ }^{16}$

$\mathrm{Na}$ propalada reformulação de ideias, segundo o texto de Butler, havia a noção de uma sistematização teológica com o intuito de, além de institucionalizar o adventismo do sétimo dia, clarificar e, principalmente, distingui-los de todos os outros. Nesse movimento, o conceito de santificação é grandemente abordado e divulgado, mantendo a práxis de Miller, mas também através de centenas de citações em dezenas de livros. Nessa fase, especificamente com o intuito real e urgente de fazer dos adventistas do sétimo dia um grupo distinto e livre de fanatizações, muitos esforços foram empreendidos no sentido de publicar e divulgar ao maior número de pessoas

14 É quase impossível não notar a semelhança da frase "nosso campo é o mundo" de White com a frase "o mundo é minha paróquia, de John Wesley, encontrada em WHITEHEAD, John. The Life of the Rev. John Wesley, M.A.: Some Time Fellow of Lincoln College. Oxford. Boston: Dow \& Jackson, 1845, p. 351.

15 WHITE, Ellen. Sowing beside all waters. Pacific Union Recorder. Westlake Village, CA: 18 de Julho de 1907.

16 BUTLER, Jonathan, NUMBER, Ronald L. The Disappointed: Millerism and Millenarianism in the nineteenth century. Knoxville: University of Tennessee Press, 1993, p. 199. Conforme o original: "First, the movemente did not emerge simply as a separate Adventist body, but rather in disappointment about the Advent and after the reformulation of ideas; second, from the beginning, its millenarianism was one among several concerns, as the group not only preache the Advent but the conditions for it; third, these conditions were validated by divine inspiration, whereby the group acquired an independ source of inspiration, apart from the Scriptures (...); fourth, the movemente established a professional ministry which opened the way to other specialized agencies that all disengaged it from more egalitarian origins; fifth, ate accretion of concerns for education, diet, medical care, religious liberty, and sabbatarianism further advanced its denominationalization both ideologically and institutionally".

Protestantismo em Revista | São Leopoldo | v. 45, n. 02 | p. 100-110| Jul./dez. 2019 
que não professavam a nova fé, os ideais adventistas do sétimo dia, sendo a doutrina da santificação uma das mais abordadas, embora não necessariamente de forma direta, mas nas entrelinhas, principalmente a partir da leitura das obras de Ellen White.

No tocante aos grupos fanáticos oriundos de Miller e suas acepções com temas diretamente relacionados à santificação, muitos são os casos claros de deturpação dos textos bíblicos no contexto de uma teologia descabida e sem lastro ou pressuposto teológico. Nesse sentido, não sem razão, o milerismo foi considerado como a doutrina religiosa da imediata destruição do mundo "que foi extensivamente ensinada neste país pelo Sr. Miller e outros, durante dois ou três anos atrás e pelo menos 32 pacientes foram recebidos em hospitais psiquiátricos sob o diagnóstico de insanidade atribuída ao Milerismo" de acordo com o The American Journal of Insanity. ${ }^{17}$ Os mais claros exemplos dessa deturpação, excitação e exagero podem ser visualizados nas palavras de Schwarz e Greenleaf:

Provavelmente, a prática mais radical, finalmente promovida por Pickands e Enoch Jacobs, editor do Day Star [jornal milerita], era o casamento espiritual. Afirmando que Cristo já tinha vindo, eles asseveravam que estavam no Céu; portanto, não deviam se casar ou darse em casamento. Usavam a declaração de Cristo de que o homem devia deixar pai, mãe, esposa e filhos para justificar o abandono de suas famílias e a formação de uniões espirituais, desprovida de sexo, com novos parceiros. Jacobs finalmente levou seus seguidores para uma colônia shaker. Igualmente bizzara era a crença, mantida por alguns, de que eles tinham agora passado para o grande sábado milenar de Cristo e não deviam fazer trabalho secular de espécie alguma. ${ }^{18}$

Portanto, para nortear os princípios básicos dessa nova fé, ao mesmo tempo em que combatiam os grupos por eles mesmos considerados fanáticos, mas que se utilizavam da alcunha de "adventistas", foi preciso recorrer ao lastro teológico dos reformadores protestantes, principalmente de cunho wesleyano - mas não só - o que aconteceu quase que de forma natural visto que os maiores vultos da igreja nessa época eram oriundos da Igreja Metodista. ${ }^{19}$

Não se cansou Ellen White de escrever elogiosamente sobre os reformadores do passado, citando Calvino mais de 40 vezes em sua obra; 80 vezes John e Charles Wesley, especificamente o trabalho deste acerca da santificação pessoal, enfatizando suas biografias. Jonathan Edwards aparece indiretamente pelo menos uma dúzia de vezes, embora de forma expressa seu nome esteja contido no apêndice da primeira edição do clássico - O Grande Conflito. ${ }^{20}$ Finalmente, Lutero

17 The American Journal of Insanity. Edited by The Officers of the New York State Lunatic Asylum, Utica, Vol. I: Bennet, Backus \& Hawley, 1844-45, p. 249-250.

18 SCHWARZ W. Richard, GREENLEAF, Floyd. Portadores de luz: história da Igreja Adventista do Sétimo Dia. Engenheiro Coelho: Imprensa Universitária Adventista, 2009, p. 54.

19 Dezenas de artigos e/ou capítulos de livros foram escritos pelos adventistas do sétimo dia sobre esse assunto, inclusive sob o prisma da Psicologia, ainda que incipiente na segunda metade do século XIX, demonstrando mais uma vez a utilização do cientificismo do século em questão para subjugar grupos considerados minoritários. Este tema foi trabalhado pelo francês Michel Foucault, principalmente em uma das suas obras clássicas, a Arqueologia do Saber. Em Ellen White, o artigo - A Mente Fanática, encontrado em seu livro Mente, Caráter e Personalidade (WHITE, Ellen. Mind, Character and Personality, vol I. Nashville: Southern Publishing Association, 1977, p. 43) aborda a questão da "carne santa", onde alguns membros ditos adventistas afirmavam não mais serem pecadores. Ela aproveitou o ensejo, mais uma vez, para escrever sobre a verdadeira santificação.

20 Em Ellen White, muito mais a prática de Jonathan Edwards foi por ela apreendida, por meio William Miller, que sua obra em si. Edwards, como precursor do primeiro grande reavivamento nos Estados Unidos, ainda no final do século

Protestantismo em Revista | São Leopoldo | v. 45, n. 02 | p. 100-110| Jul./dez. 2019

Disponível em: <http://periodicos.est.edu.br/index.php/nepp> 
é citado 900 vezes em toda a sua obra, já desde a primeira, ainda em 1844, e durante os seus setenta anos de ministério.

Procedendo dessa maneira, a igreja poderia se afirmar protestante, ao concordar com os célebres reformadores e - ao mesmo tempo - agir (segundo a própria denominação afirmava) além do protestantismo, promovendo um trabalho de verdadeiro reavivamento e, portanto, santificação. Clarificando, Whidden, explicita que:

somos [os adventistas] inteiramente protestantes no sentido de que tomamos a autoridade bíblica como última instância em questões de fé e prática (ao contrário da tradição e autoridade eclesiásticas e mesmo de profetas pós-bíblicos ou de revelações), e enfatizamos a justificação pela fé e não as obras humanas como base da salvação. (...) além disso, temos importantes e apropriados elementos oriundos do (1) wesleyanismo/arminianismo, especialmente na nossa forma de governo eclesiástico, como também no respeito de Deus pela integridade da escolha humana e na ênfase à restauração da simplicidade primitiva da igreja do Novo Testamento, edificando "as antigas ruínas", reparando as "brechas" e restaurando as "veredas para que o país se torne habitável" e (2) da tradição batista, com sua ênfase no batismo dos crentes por imersão e a liberdade religiosa. Estamos plenamente de acordo, portanto, com a ortodoxia básica da tradição cristã e somos inteiramente protestantes. ${ }^{21}$

A nova religião incipiente é diversa da teologia luterana, principalmente no tocante à questão da santificação visto que:

os adventistas querem afirmar a justificação pela fé e a "presença" de Jesus no sacramento da Santa Ceia. O adventismo, entretanto, não tem se sentido confortável com a ênfase luterana confessional na "fé somente", que tende a excluir a ênfase na santificação. ${ }^{22}$

Tal declaração pressupõe, portanto, a dialética constante oriunda do binômio fé e obras pincelada em toda a teologia adventista, mas que, nesse ponto, se aproxima da concepção metodista, visto que Wesley advertiu que a justificação não devia ser depreciada a fim de "exaltar o estado de santificação completa". Ao mesmo tempo, a ênfase no sola fide não deveria excluir a necessidade de se incitar ao arrependimento e "às obras próprias do arrependimento", antes da justificação. ${ }^{23}$ Aliás, Wesley, de acordo com Gundry, dá à Lei a mesma acepção que Ellen White, exaltando seu papel na busca pela santificação pessoal, ao afirmar que:

Wesley relaciona o cumprimento das obrigações da lei moral ao processo e propósito da santificação, em vez de relacioná-lo às concepções mais objetivas da ortodoxia reformada, que considera o ato de justificação do crente o cumprimento e a satisfação da exigência moral da Lei. (...) [ele] sempre considerou a Lei boa e santa. Para ele, não há a forte tensão entre Lei e Evangelho que permeia a teologia de Lutero. ${ }^{24}$

XVIII, abriu caminho ao posterior movimento Holiness e, exatamente por isso, ao mais caro dos pontos do adventismo do sétimo dia, ou seja, a santificação. De qualquer forma, há interessantes semelhanças, inclusive linguísticas, entre o pequeno manuscrito de Edwards, The Beauty of the World (EDWARDS, Jonathan. Images or Shadows of Divine Things. New Haven: Yale University Press, 1948, p. 135-137) e o primeiro capítulo de Passos para Cristo, (WHITE, Ellen. Steps to Christ. Mountain View: Pacific Press Publishing, 1956, p. 9-11) seu livro mais vendido, indicando, talvez, maior proximidade entre os dois autores.

21 WHIDDEN, Woodrow. Ellen White e a Humanidade de Cristo. Tatuí: Casa Publicadora Brasileira, 2004, p. 109.

22 WHIDDEN, 2004, p. 110.

23 HEITZENRATER, Richard. Wesley e o povo chamado metodista. São Bernardo do Campo: Edteo, 1996, p. 152.

24 GUNDRY, Stanley (Org.) Cinco perspectivas sobre a santificação. São Paulo: Editora Vida, 2006, p. 29.

Protestantismo em Revista | São Leopoldo | v. 45, n. 02 | p. 100-110| Jul./dez. 2019

Disponível em: <http://periodicos.est.edu.br/index.php/nepp> 
A construção do conceito de santificação por Ellen White passa pela delimitação da própria esfera denominacional, em oposição aos "adventistas espúrios", da mesma forma que quer se colocar ao lado do protestantismo historicamente constituído, sem, contudo, perder seu fervor inicial reavivamentista e em busca de santificação, que é considerado o grande elemento adicional desta para as outras denominações. Seria essa dinâmica adventista da santificação que constituiria a "reforma dentro da reforma" embora o processo lento dessa práxis em doutrina muitas vezes confundisse o adventista leigo. De acordo com Knight:

Por demasiado tempo os adventistas pensaram na perfeição de caráter em termos de uma lista de coisas permitidas e proibidas (principalmente proibidas). Por isso, associaram a perfeição de caráter a coisas tais como vida saudável, forma de observar o sábado ou maneira de vestir. Alguns chegaram mesmo a pensar que podiam desenvolver um caráter perfeito evitando toda espécie de pecado. Mas essa não é a ideia bíblica de perfeição de caráter. Na Bíblia e nos escritos de Ellen White, perfeição de caráter não é coisa negativa, mas positiva. Não se trata de algum pecado que evitamos, mas de uma qualidade de vida expressa dia-a-dia. ${ }^{25}$

Ainda assim - e por isso mesmo, ou seja, por essa propalada reforma dentro da reforma os adventistas do sétimo dia não se livraram do caráter fortemente anabatista do movimento, posteriormente assumido e publicizado por suas lideranças eclesiásticas. O que fazia seus membros se situarem entre o protestantismo histórico e o anabatismo era justamente o caráter experiencial da religião pela afirmação prática da necessidade de santificação, ao abordar questões sequer levantadas pelo próprio Wesley, que dedicou não pequena parte de seus escritos nesse sentido ${ }^{26}$. Além disso, até o ano de 1888, tiveram os adventistas grandes dificuldades de entender de fato, a questão da justificação pela fé. É precisamente por causa desse princípio da experiência que Tillich escreve:

O princípio da experiência foi preservado por movimentos sectários (amplamente dependentes do entusiasmo dos franciscanos radicais) antes e durante a Reforma. Um entusiasta evangélico como Tomás Müntzer tinha quase todos os traços característicos daquilo que chamamos hoje de experiência existencial, inclusive os elementos de ansiedade e desespero, a situação limite e a experiência da falta de sentido. E, por outro lado, ele tinha a experiência extática de um poder Espiritual que o conduzia e guiava nas decisões práticas de sua vida pessoal ou social. Embora a vitória da autoridade eclesiástica ou bíblica em todas as igrejas europeias e a ascensão da ortodoxia clássica tenham suprimido o princípio da experiência, nunca o erradicaram. O princípio da experiência reapareceu com toda a força no pietismo continental e no independentismo anglo-americano, no metodismo e no evangelicalismo. Nestas formas, ele sobreviveu ao período do iluminismo e encontrou sua expressão teológica clássica no método teológico de Schleiermacher. ${ }^{27}$

Dificilmente outro teólogo poderia com maior propriedade definir a situação especifica das denominações concordantes com este princípio, como no caso da Igreja Adventista do Sétimo Dia, visto que, havia naquele período um senso comum de que a denominação não seria mais que uma

25 KNIGHT, George R. A mensagem de 1888. Tatuí: Casa Publicadora Brasileira, 2004, p. 192.

26 Wesley, assim como Calvino, concorda que a perfeição é obra do Espírito Santo, embora no famoso sermão 40, não seja essa acepção tão clara, fato que o levará a escrever sua Explicação Clara da Perfeição Cristã. Em Ellen White, a conceituação ainda padece em algumas dificuldades quando descontextualizadas, levando a entender que a perfeição ou santificação são - obras totalmente humanas. Entre os pontos - além de Wesley, cito, entre muitos outros exemplos, a santificação através da alimentação como ponto principal.

27 TILLICH, Paul. Teologia Sistemática. São Leopoldo: Sinodal, 2005. 5a Edição Revista, p. 56.

Protestantismo em Revista | São Leopoldo | v. 45, n. 02 | p. 100-110| Jul./dez. 2019

Disponível em: <http://periodicos.est.edu.br/index.php/nepp> 
seita. ${ }^{28}$ Isso pode ser facilmente visualizado a partir da importância da doutrina do Sábado, cultivada por seus adeptos, especificamente quando este dia é entendido a partir do conceito de santificação segundo a teologia adventista.

Conforme White, santificação é clamada pelos professos cristãos que ignoram o dia sagrado de descanso divino por um Sábado espúrio. Assim, cristãos que não guardam o Sábado podem, portanto, almejar a santificação. Porém, há nesse caso um desconhecimento do significado "da verdade" do Sábado e, principalmente, da relação entre este dia e a graça divina. Para os adventistas, a Lei não está sob hipótese nenhuma destituída da graça de Deus; pelo contrário, a Lei é graça e está em harmonia perfeita com ela. Exatamente por isso, a Lei não foi anulada pela graça e não há distinção entre uma e outra, tanto no Antigo quanto no Novo Testamento. ${ }^{29}$ Portanto, não guardar um dos preceitos da Lei implica não imitar Cristo, ou seja, Aquele que é nosso único modelo a ser imitado. Dessa forma, defende-se White ao afirmar que "Deus não usa sua graça para tornar sua lei sem efeito ou mudá-la de lugar. A graça de Deus e a lei de Seu reino estão em perfeito harmonia; elas andam lado a lado."30

Quanto Paul Tillich fala em ansiedade e desespero, situação limite e falta de situaçãolimite, esses termos podem ser equilibrados, no adventismo do sétimo dia, justamente pelo poder espiritual extático da denominação, dentre outros, através da voz profética de Ellen White. A partir de seus sermões e escritos sobre o tema da santificação ela minimizava a ansiedade causada pelo atraso no retorno do Senhor e a sistematização teológica da igreja - dando a entender que essa volta poderia ser um tanto demorada ainda- conclamando seus membros ao trabalho e ao desapego de si, afirmando que apenas a partir dele esse sentimento poderia ser minimizado. Segundo ela (1998):

verdadeira santidade é integridade no serviço de Deus. Esta é a condição da verdadeira vida cristã. Cristo requer a entrega sem reservas, o serviço não dividido. Exige o coração, a mente, a alma e as forças. O eu não deve ser acariciado. Quem vive para si mesmo não é cristão. ${ }^{31}$

\section{Considerações Finais}

O movimento milerita, em virtude da brevidade do retorno de Cristo, não expressou o menor interesse em produzir qualquer texto que abordasse assunto outro que não a própria Parousia. Assim, não pode ser encontrado em escritos pertencentes ao grupo, ao menos em uma primeira lida, autores que oriundos de diferentes denominações tivessem em maior ou menor grau produzido algo sobre o tema da santificação. De todo modo, a práxis daquele grupo viria a influenciar de forma inquestionável certos modos de pensar dos adventistas do sétimo dia. Práticas essas que culminavam precisamente com a premissa da santificação em seus mais distintos aspectos.

Basicamente a partir da construção do conceito de santificação que a identidade adventista pós-milerismo é fundada e é justamente essa construção que faz a ponte entre o agora (a partir do

28 "Prova" disso é sua constituição enquanto igreja no início da década de 1860, além do fato de Ellen White nunca ter sido ordenada nem ter assumido oficialmente nenhum cargo e, mesmo por parte de alguns na liderança, à época, seu "suposto" dom profético não ter sido necessariamente benfazejo em todas as ocasiões, por conta de sua não concordância com alguns assuntos. Em suma, como os profetas bíblicos, foi uma outsider mesmo "sua própria terra". WHITE, Elle. The Necessity of Connection whith Christ. Advent Review and Sabbath Herald. 07/05/1889, p. 7.

WHITE, Ellen. God's amazing grace. Washington, DC: Review and Herald Publishing Association, 1973, p. 10.

31 WHITE, Ellen. Parábolas de Jesus. Tatuí: Casa Publicadora Brasileira, 11a Edição, 1998, p. 48-49.

Protestantismo em Revista | São Leopoldo | v. 45, n. 02 | p. 100-110| Jul./dez. 2019 
trabalho missionário e todos os departamentos da igreja) e o porvir (onde a centralidade da mensagem pulsa mais forte). Foi a partir desse equilíbrio, ano após ano, que através do tema central da santificação a mensagem da salvação pela graça, tão cara aos protestantes, finalmente ecoou nos adventistas do sétimo dia. Hodiernamente, os mesmos autores do passado denominacional ainda continuam sendo lidos e suas práticas incentivadas.

\section{Referências}

BUTLER, Jonathan, NUMBER, Ronald L. The Disappointed: Millerism and Millenarianism in the nineteenth century. Knoxville: University of Tennessee Press, 1993.

DARIUS, Fábio Augusto. O reavivamento milerita (1831-1844): esperando Cristo voltar. Protestantismo em Revista, v. 18, p. 56-65, 2009.

DARIUS, Fábio Augusto; WACHOLZ, Wilhelm. De corpo, alma e espírito: apontamentos históricos e teológicos acerca do tema santificação na obra holística de Ellen White. Escola Superior de Teologia, São Leopoldo, RS, 2014.

EDWARDS, Jonathan. Images or Shadows of Divine Things. New Haven: Yale University Press, 1948.

ELIAS, Nobert; SCOTSON, John. Os estabelecidos e os outsiders: sociologia das relações de poder a partir de uma pequena comunidade. Rio de Janeiro: Jorge Zahar, 2000.

GUNDRY, Stanley (Org.) Cinco perspectivas sobre a santificação. São Paulo: Editora Vida, 2006.

HEITZENRATER, Richard. Wesley e o povo chamado metodista. São Bernardo do Campo: Edteo, 1996.

FEDERAÇÃO LUTERANA MUNDIAL; ASSOCIAÇÃO GERAL DA IGREJA ADVENTISTA DO SÉTIMO DIA. Lutherans and adventists in conversation: report and papers presented 1994-1998. Genebra: Federação Luterana Mundial; Silver Spring: Associação Geral da Igreja Adventista do Sétimo Dia, 2000.

KNIGHT, George R. A mensagem de 1888. Tatuí: Casa Publicadora Brasileira, 2004.

KNIGHT, George. Em busca de identidade: o desenvolvimento das doutrinas adventistas do sétimo dia. Tatuí: Casa Publicadora Brasileira, 2005.

KUHN, Thomas. A estrutura das revoluções científicas. São Paulo: Perspectiva, 1992.

MAXWELL, C. História do Adventismo. Santo André: Casa Publicadora Brasileira, 1982.

SCHWARZ W. Richard, GREENLEAF, Floyd. Portadores de luz: história da Igreja Adventista do Sétimo Dia. Engenheiro Coelho: Imprensa Universitária Adventista, 2009.

The American Journal of Insanity. Edited by The Officers of the New York State Lunatic Asylum, Utica, Vol I. Utica: Bennet, Backus \& Hawley, 1844-45.

TILLICH, Paul. Teologia Sistemática. São Leopoldo: Sinodal, 2005. 5a Edição Revista.

TIMM, Alberto. Antecedentes históricos da interpretação bíblica adventista. In: REID, GEORG (Org.). Compreendendo as Escrituras: uma abordagem adventista. Engenheiro Coelho: UNASPRESS, 2007.

WHIDDEN, Woodrow. Ellen White e a Humanidade de Cristo. Tatuí: Casa Publicadora Brasileira, 2004.

Protestantismo em Revista | São Leopoldo | v. 45, n. 02 | p. 100-110| Jul./dez. 2019

Disponível em: <http://periodicos.est.edu.br/index.php/nepp> 
WHITE, Ellen. The Necessity of Connection whith Christ. Advent Review and Sabbath Herald. 07/05/1889.

WHITE, Ellen. Atos dos Apóstolos. Tatuí: Casa Publicadora Brasileira, 2007, p. 549.

WHITE, Ellen. God's amazing grace. Washington, DC: Review and Herald Publishing Association.

WHITE, Ellen. Mind, Character and Personality, vol I. Nashville: Southern Publishing Association, 1977.

WHITE, Ellen. Parábolas de Jesus. Tatuí: Casa Publicadora Brasileira, 11a Edição, 1998.

WHITE, Ellen. Primeiros Escritos. Tatuí: Casa Publicadora Brasileira, 2007.

WHITE, Ellen. Sowing beside all waters. Pacific Union Recorder. Westlake Village, CA: 18 de Julho de 1907.

WHITE, Ellen. Steps to Christ. Mountain View: Pacific Press Publishing, 1956.

WHITEHEAD, John. The Life of the Rev. John Wesley, M.A.: Some Time Fellow of Lincoln College. Oxford. Boston: Dow \& Jackson, 1845. 